\title{
Naja ashei venom induces mitochondria-mediated apoptosis in human colorectal cancer cells
}

\author{
Natalia Rozman Antolikova1\#, Martin Kello2\#, Martina Zigova², Viera Tischlerova 1,2, \\ Vladimir Petrilla ${ }^{3}$, Zdenko Pirnik 4,5 , Gabriela Mojzisova 6 and Jan Mojzis²区
}

'Department of Pharmacology and Toxicology, University of Veterinary Medicine and Pharmacy, Komenského 73, Kosice, Slovakia; ${ }^{2}$ Department of Pharmacology, Faculty of Medicine, P.J. Safarik University, Tr. SNP 1, Kosice, Slovakia; ${ }^{3}$ Department of Anatomy, Histology and Physiology, University of Veterinary Medicine and Pharmacy, Komenského 73, Kosice, Slovakia; 4Institute of Physiology, Faculty of Medicine, Comenius University in Bratislava, Sasinkova 2, Bratislava; Institute of Experimental Endocrinology BMC, Slovak Academy of Sciences, Dúbravska cesta 9, Bratislava; ${ }^{6}$ Department of Experimental Medicine, Faculty of Medicine, P.J. Safarik University, Tr. SNP 1, Kosice, Slovakia

In the present study, we investigated the antiproliferative activity of Naja ashei full venom (NAV) on human colorectal cancer cells. The NAV-induced antiproliferative effect was associated with cell cycle arrest in $S$ phase and increased number of cells with sub G0/G1 DNA content, which is considered a marker of apoptosis. Apoptosis has also been confirmed with annexin V/PI staining. Furthermore, flow cytometric analysis revealed loss of mitochondrial membrane potential with concomitant increase in cytochrome $c$ and Smac/DIABLO protein content. These effects were associated with the activation of caspase- 9 and caspase- 3 , as well as with PARP cleavage. Moreover, phosphorylation of antiapoptotic $\mathrm{Bcl}-2$ protein in NAV-treated HCT116 was observed. In conclusion, our study for the first time documented antiproliferative/ pro-apoptotic effect of NAV in colorectal cancer cells. Our results strongly suggest the involvement of mitochondria in NAV induced apoptosis of cancer cells. Future studies are needed to further examine the potential of NAV in the treatment of colon cancer.

Key words: Naja ashei venom, colorectal cancer cells, antiproliferative effect, apoptosis

Received: 15 February, 2019; revised: 08 April, 2019; accepted: 26 April, 2019; available on-line: 07 June, 2019

『e-mail: jan.mojzis@upjs.sk

\#These authors contributed equally to this work.

Acknowledgments of Financial Support: This publication is the result of the project implementation: Medical University Science Park in Košice (MediPark, Košice - Phase II) ITMS2014+ 313011D103 supported by the Operational Programme Research \& Innovation, funded by the ERDF

Abbreviations: CRC, colorectal cancer; BrdU, 5-bromo-2'-deoxyuridine; MMP, mitochondrial membrane potential; MTS, methyl tetrazolium salt; NAV, Naja ashei venom; PARP, poly (ADP-ribose) polymerase; PI, propidium iodide; PS, phosphatidylserine

\section{INTRODUCTION}

Despite improvements in treatment and diagnosis, cancer is one of the most common causes of death in the world. It is estimated that in 2018, there were over 18 million new cancer cases and 9.6 million deaths from cancer (Bray et al., 2018). Among all cancers, colorectal cancer (CRC) ranks second in terms of mortality, accounting for about 1 in 10 cancer deaths in 2018 (Bray et al., 2018). In the current treatment of CRC, chemotherapy play an important role, and anti-cancer drugs such as platinum derivatives, antimetabolites or topoisomerase inhibitors are most commonly used (Rejhova et al., 2018). On-going progress in the treatment of CRC significantly improves the prognosis of patients, however, the side effects of antineoplastic drugs and their low specificity continue to be responsible for a reduced quality of life (Coppola et al., 2018). Therefore. the new compounds for CRC treatment are needed. The largest source of bioactive chemicals is nature. Numerous articles have documented antiproliferative/anticancer effects of plant-derived compounds known as a phytochemicals (Dutt et al., 2018; Einbond et al., 2017; Iqbal et al., 2018). In our laboratory we have also documented antiproliferative effect of several flavonoids, chalcones or indole phytoalexins (Kello et al., 2014; Kello et al., 2017; Takac et al., 2018; Tischlerova et al., 2017). However, the antiproliferative effect of agents from animal sources was studied only marginally, as compared to plant-derived compounds. Among those, the snake venoms attracted attention for possible use as anticancer agents.

The anticancer activity of snake venom was first reported by Calmette and co-workers in 1933 (Calmette et al., 1933), who observed the antitumor effect of cobra venom in adenocarcinoma cells. Since then, several in vivo and in vitro experiments have shown that snake venoms can inhibit the growth and proliferation of various types of cancer cells (Liu et al., 2014).

Although the precise mechanism of anti-cancer effect of snake venoms remains to be elucidated, the existing results indicate the multitarget action including apoptosis induction (Park et al., 2009), modulation of signalling pathways associated with cell survival or death (Song et al., 2012), reactive oxygen species (ROS) production (Park et al., 2012) and mitochondrial disruption (Fakhri et al., 2017). Moreover, the ability of snake venoms to inhibit angiogenesis or metastasis has also been documented (Calderon et al., 2014; Kerkkamp et al., 2018).

In the present study, the effect of Naja ashei venom (NAV) on colon cancer cells was investigated. Naja ashei is an African spitting cobra species which has been classified as a separate species in 2007 (Wuster \& Broadley, 2007).

According to our knowledge, no study focused on the pro-apoptotic effect of NAV has been published so far. This study is a novel investigation of the effect of NAV on apoptosis in human colorectal cancer cells. 


\section{MATERIAL AND METHODS}

Snake venom collection. The full Naja ashei venom samples were obtained from two adult snakes, which were captured and officially imported from Kenya. Venom was extracted in the Pata breeding garden near Hlohovec (Slovakia), under the veterinary certificate No. CHEZ-TT-01. After extraction, the venom was stored at $-20^{\circ} \mathrm{C}$ (transport temperature) and then moved to $-80^{\circ} \mathrm{C}$ for deep freezing.

The breeding garden serves as a quarantine station for imported animals and is an official importer of exotic animals from around the world, having the permission of the State Nature Protection of the Slovak Republic under the No. 03418/06, the trade with endangered species of wild fauna and flora and on amendments to certain laws under Law no. 237/2002 Z.z.

Cell culture. The human colorectal cancer cell line (HCT116) was cultured in RPMI 1640 medium and the human dermal fibroblast cell line (HDF; non-cancer) was cultured in DMEM with sodium pyruvate (Biosera, Kansas City, MO, United States). The growth media were supplemented with $10 \%$ fetal bovine serum, penicillin $(100 \mathrm{IU} / \mathrm{mL})$ and streptomycin $(100 \mu \mathrm{g} / \mathrm{mL})$ (all Invitrogen, Carlsbad, CA, United States). Cells were cultured in $5 \% \mathrm{CO}_{2}$ in humidified air at $37^{\circ} \mathrm{C}$. Cell viability, estimated with trypan exclusion assay before each experiment, was greater than $95 \%$.

MTS cell proliferation/viability assay. MTS assay was used to determine the effects of NAV (5.7-17.1 $\mu \mathrm{g} /$ $\mathrm{ml}$ ) on the metabolic activity of both HCT116 and HDF cells. After 72 hours of incubation, $10 \mu \mathrm{L}$ of MTS (Promega, Madison, WI, USA) was added to each well according to the CellTiter $96^{\circledR}$ Aqueous One Solution Cell Proliferation Assay protocol. After minimum 1-hour incubation, the absorbance was measured at $490 \mathrm{~nm}$ using the automated Cytation ${ }^{\mathrm{TM}} 3$ Cell Imaging Multi - Mode Reader (Biotek, Winooski, VT, USA). The absorbance of the control wells was taken as $1.0(100 \%)$ and the results were expressed as a percent of the control. All experiments were performed in triplicate.

BrdU cell proliferation assay. Cell proliferation was confirmed using the 5-bromo-2'-deoxyuridine (BrdU) Cell Proliferation Assay Kit (Roche Diagnostics, Man-

Table 1. Flow cytometry cell staining.

\begin{tabular}{|c|c|c|}
\hline Analysis & Staining solution & Manufacturer \\
\hline \multirow{2}{*}{ Caspase activation } & Cleaved Caspase-3-PE & Cell Signaling Technology, Danvers, MA, USA \\
\hline & Cleaved Caspase-9-FITC & BIOSS Antibodies, Woburn, MA, USA \\
\hline Cytochrome c release & Cytochrome $c$ antibody (6H2) FITC conjugate & Invitrogen, Carlsbad, CA, USA \\
\hline Cleavage of PARP & $\begin{array}{l}\text { Cleaved-PARP (Asp214) XP® rabbit mAb (PE } \\
\text { Conjugate) }\end{array}$ & Cell Signaling Technology, Danvers, MA, USA \\
\hline Mitochondrial membrane potential & $\begin{array}{l}\text { TMRE (tetramethylrhodamine ethyl ester per- } \\
\text { chlorate), final concentration } 0.1 \mu \mathrm{M}\end{array}$ & Sigma-Aldrich, St. Louis, Missouri, USA \\
\hline
\end{tabular}

Bcl-2 mouse mAb (PE conjugate)

Phospho-Bcl-2 (Ser70) rabbit mAb Alexa Fluor ${ }^{\circledR}$ 488 conjugate

Cell Signaling Technology`, Danvers, MA, USA

nheim, Germany). Cells were seeded at a density of $10 \times 10^{3}$ cells/well in 96-well polystyrene microplates (SARSTEDT, Nümbrecht, Germany). Twenty-four hours after cell seeding, different concentration (5.7-17.1 $\mu \mathrm{g} /$ $\mathrm{ml}$ ) of NAV were added. After $48 \mathrm{~h}$ of treatment, cells were incubated with BrdU labelling solution $(10 \mathrm{mM}$ final concentration) for another $24 \mathrm{~h}$ at $37^{\circ} \mathrm{C}$ followed by fixation and incubation with anti-BrdU peroxidase conjugate for an additional $1.5 \mathrm{~h}$ at room temperature. Finally, after substrate reaction, the "stop solution" was added (25 $\mathrm{ml} 1 \mathrm{M} \mathrm{H}_{2} \mathrm{SO}_{4}$ ), and color intensity was measured with an automated Cytation ${ }^{\text {TM }} 3$ Cell Imaging MultiMode Reader (Biotek). Absorbance of control wells was taken as 100\%, and the results were expressed as a percentage of the untreated control.

Cell cycle analysis. The HCT116 cells, both floating and adherent, were harvested $\left(1 \times 10^{6}\right.$ cells $) 24,48$ and 72 hours after adding NAV $(6.84 \mu \mathrm{g} / \mathrm{ml})$, washed in PBS, fixed in cold $70 \%$ ethanol and kept at $+4^{\circ} \mathrm{C}$ overnight. Prior to analysis, the cells were washed in PBS, resuspended in staining solution $(0.2 \%$ Triton X-100, $0.5 \mathrm{mg} /$ $\mathrm{ml}$ ribonuclease $\mathrm{A}$ and $0.025 \mathrm{mg} / \mathrm{ml}$ propidium iodide in $500 \mu \mathrm{l}$ PBS; all Sigma Aldrich, St. Louis, MO, USA) and incubated for 30 minutes at room temperature in the dark. The DNA content of the stained cells was analyzed using a BD FACSCalibur flow cytometer (BD Biosciences, San Jose, CA, USA). For each sample, a minimum of $1 \times 10^{4}$ cells were evaluated and the sample flow rate during analysis did not exceed 200-300 cells per second.

Apoptosis detection via externalized phosphatidylserine (PS). For apoptosis detection, the floating and adherent HCT116 cells $\left(1 \times 10^{6}\right)$ were harvested 24,48 and 72 hours after treatment with $\operatorname{NAV}(6.84 \mu \mathrm{g} / \mathrm{ml})$, washed in PBS and stained using Annexin-V-Alexa Fluor 647 conjugated antibody (Invitrogen, Carlsbad, CA, USA) for 15 minutes at room temperature in the dark. Prior to analysis the cells were stained with PI and were next observed using a BD FACSCalibur flow cytometer.

Flow cytometric analysis. HCT116 cells $\left(1 \times 10^{6}\right)$ were treated with NAV at concentration $6.84 \mu \mathrm{g} / \mathrm{ml}$ for 24, 48 and 72 hours. Floating and adherent cells were harvested, washed in PBS, split for particular analysis and stained prior to analysis (Table 1). Fluorescence was detected after 15 minutes incubation at room tempera-

Protein analysis

488

Smac/Diablo (D5S3R) rabbit mAb

Goat anti-rabbit IgG $(\mathrm{H}+\mathrm{L})$ secondary antibody conjugated with Alexa Fluor 488

Thermo Scientific, Rockford, IL, USA 


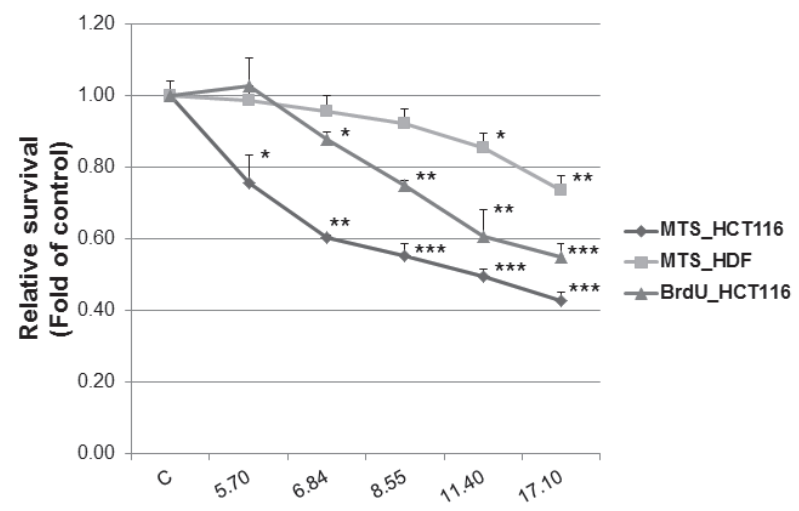

Figure 1. The effect of NAV (5.7 to $17.1 \mu \mathrm{g} / \mathrm{ml}$ ) on the metabolic activity and cell proliferation in HCT116 (as assessed with MTS and BrdU incorporation assays) and in HDF cells (as assessed with MTS assay).

Data were obtained from three independent experiments. Statistical significance of comparison with control cells (untreated) is marked as ${ }^{*} p<0.05$; ${ }^{* *} p<0.01$; ${ }^{* *} p<0.001$; and for the comparison between the cell lines is marked as ${ }^{++} p<0.01{ }^{+++} p<0.001$.

ture in the dark using a BD FACSCalibur flow cytometer. A minimum of $1 \times 10^{4}$ events was used per analysis.

Statistical analysis. The results are expressed as mean \pm S.D. The statistical analysis of the data was performed using standard procedures, with one-way ANOVA followed by the Bonferroni multiple comparisons test. Values of $p<0.05$ were considered statistically significant.

\section{RESULTS}

\section{MTS cell proliferation/viability assay and BrdU cell proliferation assay}

The metabolic activity and cell proliferation on the human cancer cell line HCT116 showed that NAV inhibits cell proliferation in a dose-dependent manner. Incubation of HCT116 cells with NAV in all concentrations used, significantly decreased metabolic activity $(p<0.05-p<0.001)$. In comparison with HCT116, the effect of NAV on non-cancer HDF cells was significantly weaker (Fig. 1). To confirm antiproliferative effect of NAV, we used BrdU cell proliferation assay which detected 5-bromo-2'-deoxyuridine (BrdU) incorporated into cellular DNA during cell proliferation. With the exception of the lowest concentration $(5.7 \mu \mathrm{g} / \mathrm{ml})$, NAV significantly decreased incorporation of BrdU into DNA, i.e. inhibited cell proliferation $(p<0.05-p<0.001)$.

Based on of MTS and BrdU assays, we selected a concentration of $6,84 \mu \mathrm{g} / \mathrm{ml}$ for all other experiments.

Cell cycle analysis. Cell cycle phases distribution was determined using flow cytometric analysis of HCT116 cells after NAV treatment for 24, 48 and 72 hours. The results showed a significant increase in the number of cells with sub-G0/G1 DNA content after $24 \mathrm{~h}$ treatment, which increased after 48 and 72 hours. At the same time, an increase in the population of cells in $\mathrm{S}$ phase was observed after 24 and 48 treatment, which suggested cell cycle arrest (Table 2, Fig. 2). Accordingly, a significant concomitant reduction of populations in $\mathrm{G} 1$

Table 2. Percentage analysis of the cell cycle phases in the NAV-treated (6.84 $\mu \mathrm{g} / \mathrm{ml}) \mathrm{HCT} 116$ cells, determined with the use of flow cytometry.

\begin{tabular}{llcccc}
\hline Treatment & Time $(\mathrm{h})$ & sub- $\mathrm{G}_{0} / \mathrm{G}_{1}$ & $\mathrm{G}_{1}$ & $\mathrm{~S}$ & $\mathrm{G}_{2} / \mathrm{M}$ \\
\hline & 24 & $0.92 \pm 0.17$ & $42.10 \pm 0.86$ & $27.53 \pm 1.80$ & $29.43 \pm 2.35$ \\
Control & 48 & $0.97 \pm 0.35$ & $51.40 \pm 2.61$ & $26.50 \pm 2.08$ & $21.13 \pm 2.82$ \\
& 72 & $1.82 \pm 0.44$ & $56.90 \pm 2.24$ & $20.13 \pm 1.79$ & $21.13 \pm 3.34$ \\
& 24 & $15.9 \pm 3.2^{\mathrm{b}}$ & $33.35 \pm 3.27^{\mathrm{a}}$ & $38.50 \pm 1.22^{\mathrm{b}}$ & $12.20 \pm 1.91^{\mathrm{b}}$ \\
$\mathrm{NAV}$ & 48 & $24.0 \pm 1.8^{\mathrm{c}}$ & $33.80 \pm 1.38^{\mathrm{b}}$ & $33.35 \pm 1.74^{\mathrm{a}}$ & $8.87 \pm 1.65^{\mathrm{b}}$ \\
& 72 & $39.9 \pm 3.4^{\mathrm{c}}$ & $43.45 \pm 2.3^{\mathrm{b}}$ & $9.42 \pm 2.61^{\mathrm{a}}$ & $7.25 \pm 1.18^{\mathrm{b}}$ \\
\hline
\end{tabular}

The results from three independent experiments are presented as a mean \pm SD. Statistical significance is marked as a when $p<0.05,{ }^{b} p<0.01, c p<0.001$ in comparison with the untreated cells (control). The sub- $G_{0} / G_{1}$ fraction of cells is identified as the apoptotic population.
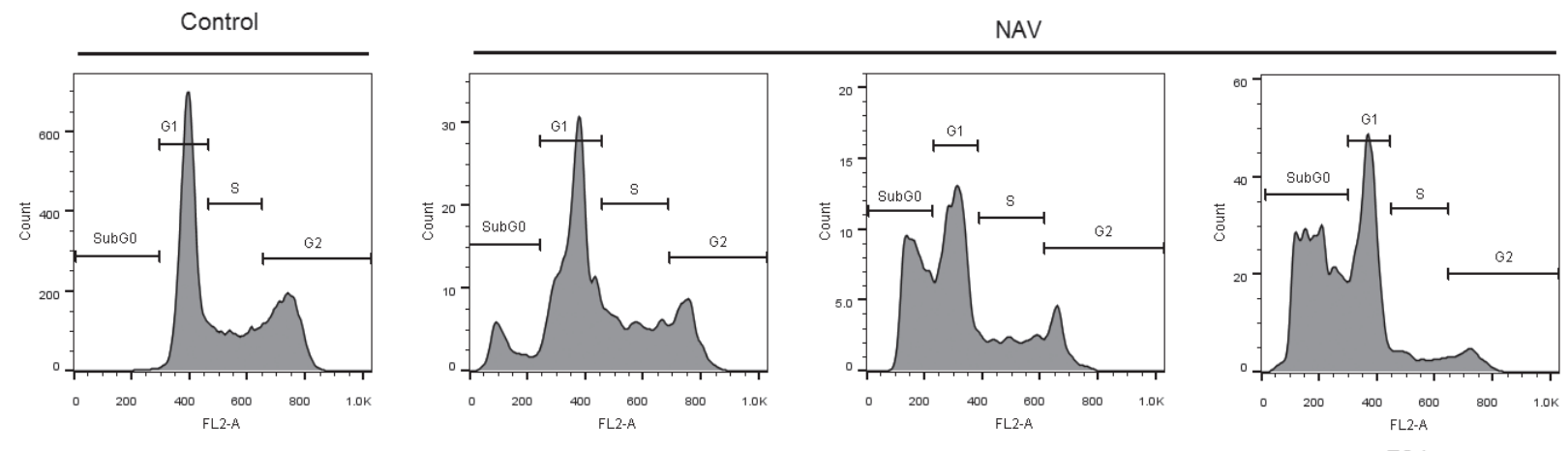

$48 \mathrm{~h}$

$72 \mathrm{~h}$

Figure 2. Cell cycle phases distribution in HCT116 cells treated with $6,84 \mu \mathrm{g} / \mathrm{ml} \mathrm{NAV}$ for 24,48 and $72 \mathrm{~h}$. 
Table 3. Annexin V/PI flow cytometry analysis of apoptosis occurrence in HCT116 cells after NAV treatment (6.84 $\mu$ g/ml).

\begin{tabular}{|c|c|c|c|c|c|}
\hline Treatment & Time (h) & $\mathrm{An}^{-} / \mathrm{Pl}^{-}$ & $\mathrm{An}^{+} / \mathrm{PI}^{-}$ & $\mathrm{An}^{+} / \mathrm{PI}^{+}$ & $\mathrm{An}^{-/ \mathrm{PI}+}$ \\
\hline \multirow{3}{*}{ Control } & 24 & $92.30 \pm 1.17$ & $0.76 \pm 0.47$ & $3.09 \pm 0.30$ & $3.85 \pm 1.01$ \\
\hline & 48 & $92.83 \pm 2.25$ & $1.14 \pm 0.49$ & $2.85 \pm 1.14$ & $3.17 \pm 0.96$ \\
\hline & 72 & $94.60 \pm 1.41$ & $0.49 \pm 0.14$ & $1.86 \pm 0.50$ & $3.03 \pm 1.00$ \\
\hline \multirow{3}{*}{ NAV } & 24 & $82.67 \pm 0.64^{a}$ & $10.40 \pm 1.66^{a}$ & $1.61 \pm 0.52$ & $5.32 \pm 1.29$ \\
\hline & 48 & $51.13 \pm 2.78^{c}$ & $24.94 \pm 2.82^{\mathrm{b}}$ & $10.27 \pm 1.42^{\mathrm{a}}$ & $13.64 \pm 1.50^{\mathrm{a}}$ \\
\hline & 72 & $33.67 \pm 3.42^{c}$ & $40.23 \pm 1.65^{c}$ & $12.46 \pm 2.1^{\mathrm{a}}$ & $13.61 \pm 2.18^{a}$ \\
\hline
\end{tabular}

The results from 3 independent experiments are presented as a percentage of An-/PI- events (living cells), An+/PI- events (cells in a stage of early apoptosis), An+/PI+ events (late apoptotic cells) and An-/PI+events (necrotic/dead cells). Statistical significance of comparison with untreated cells (control) is described as: a $p<0.05 ; \mathrm{b} p<0.01 ; \mathrm{c} p<0.001$.
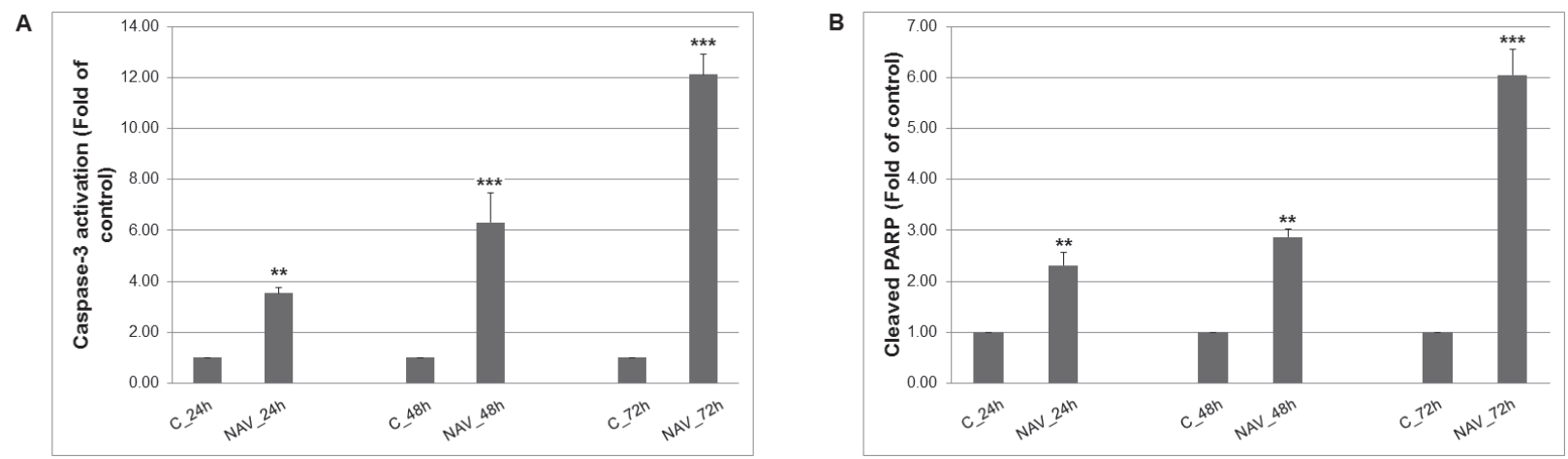

Figure 3. Effect of NAV treatment $(6.84 \mu \mathrm{g} / \mathrm{ml})$ on caspase activity and PARP cleavage.

(A) Activation of caspase-3; (B) Cleavage of PARP based on flow cytometric analysis at 24, 48 and $72 \mathrm{~h}$ after treatment. Graph shows control - normalized mean \pm S.D. for 3 independent experiments. Statistical significance of treated vs. untreated cells is shown with ${ }^{* *} \boldsymbol{p}<0.01,{ }^{* * *} \boldsymbol{p}<0.001$.

and $\mathrm{G} 2 / \mathrm{M}$ phase after 24,48 and $72 \mathrm{~h}$ after treatment was also observed. These findings suggest significant changes in cell cycle progression and induction of apoptosis in HCT116 cells treated with NAV.

Apoptosis detection, caspase-3 activation and PARP cleavage. Because the increase in the number of cells with sub-G0/G1 DNA content is a marker of apoptosis, we performed several complementary assays to confirm the apoptosis-inducing effect of NAV.

One of the earliest features of apoptosis is the translocation of phospholipid phosphatidylserine from the inner to the outer plasma membrane. Due to the high affinity of annexin $\mathrm{V}$ for phosphatidylserine, staining with annexin V-FITC conjugate is used to detect early apoptosis. A co-staining with propidium iodide $(\mathrm{PI})$ is used to distinguish between apoptotic and necrotic cells (Crowley et al., 2016). Our results showed that NAV induced a significant increase in the number of annexin $\mathrm{V}$ - positive cells with a concomitant increase in the number of PI positive cells that was time dependent (Table 3). Therefore, we suggest that apoptosis plays an important role in the death mechanisms of HCT116 cells treated with NAV.

Another characteristic feature of apoptosis is the proteolytic cleavage of poly (ADP-ribose) polymerase (PARP). This enzyme is involved in DNA repair and stability, and cleavage of PARP by caspases is considered to be a marker of apoptosis.

To confirm the apoptosis-inducing effect of NAV, we tested its influence on caspase- 3 activity and PARP cleavage. After NAV treatment, caspase-3 activity signifi- cantly increased in all the tested time periods $(p<0.01$, $p<0.001$ vs. untreated controls) (Fig. 3A). Increase in caspase-3 activity strongly correlated with PARP cleavage $(p<0.01, p<0.001$ vs. untreated controls) (Fig. 3B).

Mitochondrial membrane potential (MMP) dissipation. Mitochondria represent the key organelles affected by several extra-/intra-cellular stimuli. Dissipation of transmembrane potential $\left(\Delta \Psi_{\mathrm{m}}\right)$ is the first and a very early indicator of mitochondrial dysfunction. In our experiments, significant decrease of the MMP was observed 24, 48 and 72 hours after treatment with NAV $(p<0.001)$ (Fig. 4), indicating the activation of the mitochondrial apoptotic cell death pathway.

Mitochondrial apoptotic pathway activation. Mitochondrial changes induced by several stimuli activate intrinsic apoptotic pathway. Loss of MMP, membrane dysfunction and damage led to the activation of several proteins associated with programmed cell death, for example pro/antiapoptotic proteins, cytochrome $c$, apoptosis inhibitors and activators, etc.

Cytochrome $c$ is an important member of the mitochondrial apoptosis cascade. During apoptosis, this protein is released from mitochondria to cytosol, where it binds to Apaf-1 protein forming the apoptosome complex and triggering activation of initiator caspase-9. Our experiments showed significant changes in the release of cytochrome $c$ shortly after $24 \mathrm{~h}$ in the NAV-treated HCT116 cells (Fig. 5A). Similar effects were observed in caspase-9 activation in a time dependent manner (Fig. 5B). Concomitantly with caspase-9 activation, we observed a significant increase in Smac/DIABLO pro- 

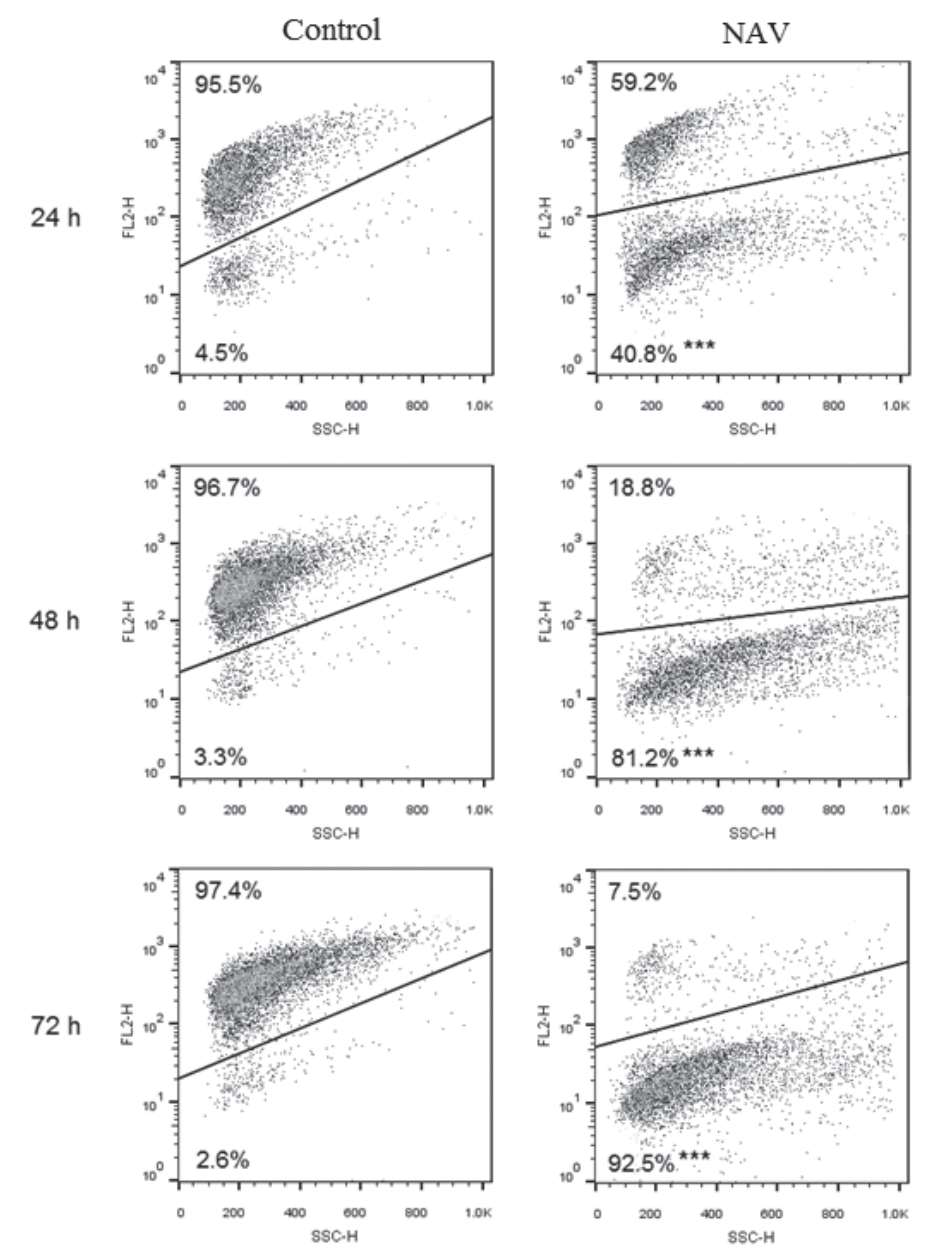

Figure 4. Representative dot-plot diagram of MMP changes in HCT116 cells after NAV treatment $(6.84 \mu \mathrm{g} / \mathrm{ml})$.

Data were obtained from three independent experiments, and significant differences versus control cells (untreated) were marked as ${ }^{* * *} p<0.001$.

tein levels (a second mitochondria-derived activator of caspases) 24 hours after HCT116 incubation with NAV (Fig. 5C).

To support our hypothesis about mitochondrial pathways involvement in cell apoptosis after the NAV treatment, we analysed $\mathrm{Bcl}-2$ protein status and activity. We observed a significant increase of $\mathrm{Bcl}-2$ protein levels in cytosol after $24 \mathrm{~h}$ of NAV treatment, which culminated after $48 \mathrm{~h}$. Moreover, the phosphorylation of Bcl-2 significantly increased in a time-dependent manner, suggested deactivation of antiapoptotic function (Fig. 6).

\section{DISCUSSION}

Snake venom, a complex mixture of different components such as peptides, proteins, enzymes and carbohydrates, possesses a variety of biological effects. Several proteins from snake venoms, in spite of their toxicity, are promising pharmaceutical agents in the field of cancer treatment ('Tan et al., 2018; Waheed et al., 2017).

The present study is the first to show the pro-apoptotic effect of Naja ashei venom in human colorectal cancer cells. Apoptosis plays a crucial role in the elimination of unnecessary cells, including the malignant cells. However, one of the typical cancer hallmarks is the ability of cancer cells to evade apoptosis, and activation of apoptotic machinery plays an essential role in the anticancer activity of several conventional antineoplastic drugs (Hanahan \& Weinberg, 2000).

Our study was designed to reveal whether NAV influences proliferation of HCT116 colorectal cancer cells and further to examine the possible mechanism of its pro-apoptotic effect. We found that viability and proliferation of NAV-treated cancer cells significantly decreased in comparison with the untreated cells. We also showed that suppression of cancer cell growth was associated with the induction of apoptosis, as revealed by several complementary assays. In the NAVtreated cell population, we detected an increase in the fraction of cells with sub-G0/G1 DNA content, which is considered a marker of apoptosis. Apoptosis was further confirmed with annexin V/PI staining and detection of cleaved PARP.

Because the mechanisms of the NAV-induced apoptosis in cancer cells have not yet been studied, in the present paper we tried to evaluate the machinery by which NAV induces apoptosis.

It is well known that mitochondria are essential for cell survival. However, there is also plentiful evidence on crucial role of mitochondria in apoptosis and several factors such as DNA damage or chemotherapeutic agents can induce mitochondria-operated apoptosis (Gillies \& Kuwana, 2014; Wang \& Youle, 2009).

Mitochondrial dysfunction can be associated with the loss of mitochondrial membrane potential $(\Delta \Psi \mathrm{m})$ (Cosentino \& Garcia-Saez, 2014) and modulation of function of $\mathrm{Bcl}-2$ proteins (Danial, 2007). The release of intermembrane space proteins such as cytochrome $c$, Smac/DIABLO or apoptosis-inducing factor into the cytosol, leads to the activation of downstream caspases to carry out the apoptosis process (Burke, 2017). We found a significant loss of MMP in the HCT116 cells after 24, 48 and $72 \mathrm{~h}$ of incubation with NAV. At the same time, we detected increased content of cytochrome $c$ in cytosol after 24, 48 and $72 \mathrm{~h}$ of treatment, as well as Smac/DIABLO protein after $24 \mathrm{~h}$ of incubation. In the NAV-treated colorectal cancer cells, we observed, as a consequence of the release of apoptosis activators, the activation of both caspase- 9 and caspase- 3 with a subsequent PARP cleavage. Similar pro-apoptotic effect of cobra venom associated with the loss of MMP and caspase- 3 activation have been recently documented by Ebrahim and co-workers (2016). Later, the ability of cobra venom from Naja oxiana to induce the loss of MMP, release of cytochrome $c$ and caspase- 3 activation was confirmed either in hepatocellular carcinoma (Seydi et al., 2017) or in colorectal carcinoma (Fakhri et al., 2017).

The Bcl-2 family of proteins plays an important role in apoptosis either as anti- or pro-apoptotic factors (Tsujimoto, 1998). Anti-apoptotic Bcl-2 protein prevents activation of apoptotic pathway by blocking the activation of caspases. It has been documented that its antiapop- 


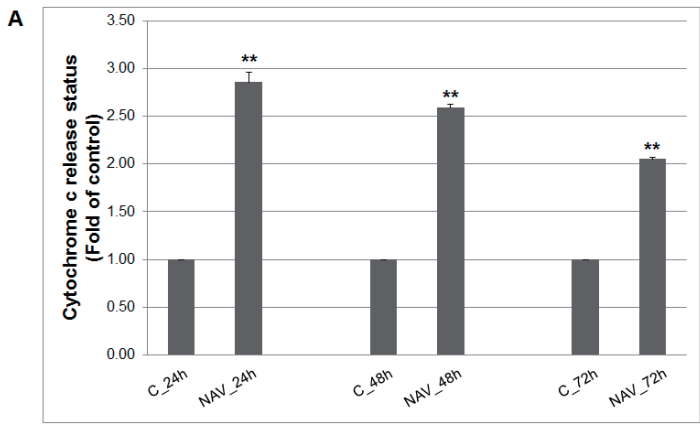

B

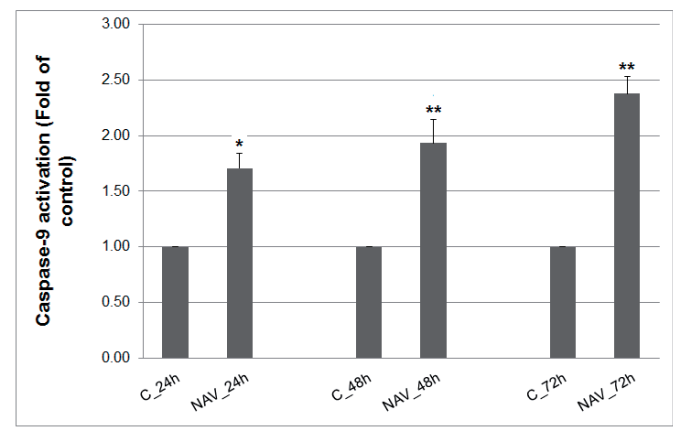

C

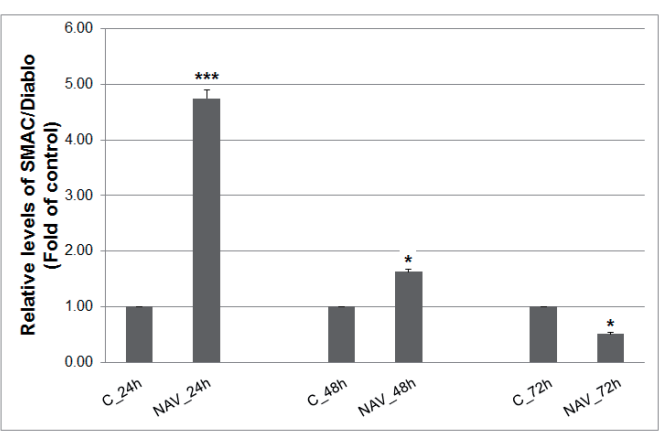

Figure 5. The release of cytochrome $c(\mathrm{~A})$, caspase-9 activation (B) and SMAC/Diablo presentation (C) in HCT116 cells 24, 48 and $72 \mathrm{~h}$ after NAV treatment $(6.84 \mu \mathrm{g} / \mathrm{ml})$, as assessed with flow cytometry analysis.

Data represents the control-normalized mean \pm S.D. for 3 independent experiments; ${ }^{*} p<0.05 ;{ }^{* *} p<0.01 ;{ }^{* * *} p<0.001$ vs. untreated cells (control). totic activity depends on its phosphorylation status, and Bcl-2 phosphorylation suppresses its anti-apoptotic function (Tamura et al., 2004). In our study we found significant increase of phosphorylated Bcl-2 after 24, 48 and $72 \mathrm{~h}$ of incubation in NAV-treated cells. Loss of Bcl-2 function can influence mitochondrial membrane integrity and cytochrome c release (Kale et al., 2018).

Due to the fact that there is no record of NAV effect on cancer cell lines in the literature, it is impossible to compare our result with others. On the other hand, recently Hus and co-workers analyzed protein composition of Naja ashei venom (Hus et al., 2018) and they found that the main components of analysed venom were threefinger toxins (3FTxs) and phospholipases $\mathrm{A}_{2}\left(\mathrm{PLA}_{2}\right)$ accounting $70 \%$ and $27 \%$ of the total venom proteins.

3FTxs is a family of non-enzymatic polypeptides found in the venom of terrestrial or sea snakes (Kini\&Doley, 2010). As documented by Hus and co-authors (2018), cytotoxin 1 (CTX1) and cytotoxin 2 (CTX2) are the most abundant proteins from 3FTxs family in the Naja ashei venom. It has been shown that both cytotoxins are potent apoptosis stimulators in cancer cells (Ebrahim et al., 2014; Wu et al., 2013). Similar to our results, CTX1 and CTX2 induced apoptosis was associated with mitochondrial dysregulation. As shown recently, the disruption of mitochondrial membranes may be the result of binding of CTX1 and CTX2 to cardiolipin (Gasanov et al., 2015).

Furthermore, $\mathrm{PLA}_{2}$, the second most common component of NAV, has also been found to possess pro-apoptotic activity. Chen and co-workers (2010) and Liu and co-workers (2009) documented the apoptosis inducing effect of the cobra PLA 2 associated with modulation of $\mathrm{Bcl}-2$ family proteins, reactive oxygen species production, loss of mitochondrial membrane potential, cytochrome $c$ release or modulation of several signalling pathways.

\section{CONCLUSION}

Taken together, our results show for the first time that NAV has potent antiproliferative effect in the colorectal carcinoma cell line. Naja ashei venom induces this effect via the induction of apoptosis through cell cycle arrest in $\mathrm{S}$ phase, an increase in the number of cells with sub-G0/G1 DNA content, mitochondrial damage, release of cytochrome $c$ and Smac/DIABLO protein with subsequent activation of caspase-9 and caspase-3. These finding suggest that NAV-induced apoptosis was mediated by the intrinsic pathway.
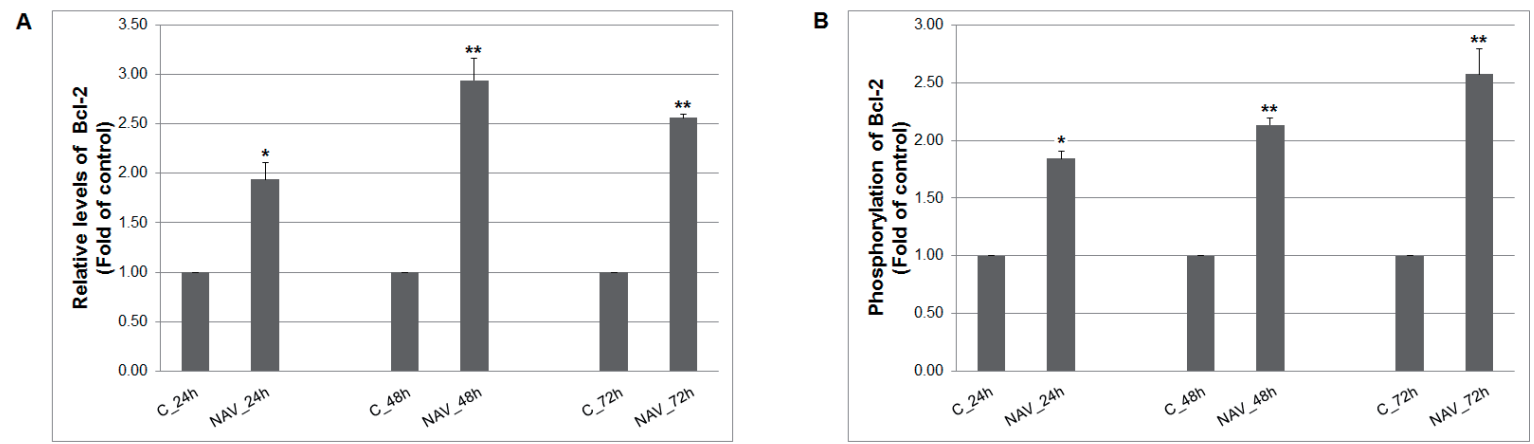

Figure 6. Analysis of mitochondrial apoptotic pathway associated proteins in HCT116 cells treated with NAV.

Relative levels (A) and activation (B) of Bcl 2 protein after NAV treatment $\left(6.84 \mu \mathrm{g} / \mathrm{ml} ;{ }^{*} p<0.05,{ }^{* *} p<0.01\right.$ vs. untreated cells (control). 


\section{REFERENCES}

Bray F, Ferlay J, Soerjomataram I, Siegel RL, Torre LA, Jemal A (2018) Global cancer statistics 2018: GLOBOCAN estimates of incidence and mortality worldwide for 36 cancers in 185 countries. CA Cancer J. Clin. 68: 394 -424. https://doi.org/10.3322/caac.21492

Burke PJ (2017) Mitochondria bioenergetics and apoptosis in cancer. Trends. Cancer 3: 857-870. https://doi.org/10.1016/j.trecan.2017.10.006

Calderon LA, Sobrinho JC, Zaqueo KD, de Moura AA, Grabner AN, Mazzi MV, Marcussi S, Nomizo A, Fernandes CF, Zuliani JP, Carvalho BM, da Silva SL, Stabeli RG, Soares AM (2014) Antitumoral activity of snake venom proteins: new trends in cancer therapy. Biomed. Res. Int. 2014: 203639. https://doi.org/10.1155/2014/203639

Calmette A, Saenz A, Costil L (1933) Effects du venin de cobra sur les greffes cancereuses et sur le cancer spontane (adeno-carcinome) de la souris. C R Acad. Sci. 197: 205-210

Coppola C, Rienzo A, Piscopo G, Barbieri A, Arra C, Maurea N (2018) Management of QT prolongation induced by anti-cancer drugs: Target therapy and old agents. Different algorithms for different drugs. Cancer Treat. Rev. 63: 135-143. https://doi.org/10.1016/j. ctrv.2017.11.009

Cosentino K, Garcia-Saez AJ (2014) Mitochondrial alterations in apoptosis. Chem. Phys. Lipids 181: 62-75. https://doi.org/10.1016/j. chemphyslip.2014.04.001

Danial NN (2007) BCL-2 family proteins: critical checkpoints of apoptotic cell death. Clin. Cancer Res. 13: 7254-7263. https://doi. org/10.1158/1078-0432.CCR-07-1598

Dutt R, Garg V, Khatri N, Madan AK (2018) Phytochemicals in anticancer drug development. Anticancer Agents Med. Chem. https://doi. org/10.2174/1871520618666181106115802

Ebrahim K, Shirazi F.H, Vatanpour H, Zare A, Kobarfard F, Rabiei H, (2014) Anticancer activity of cobra venom polypeptide cytotoxin-ii against human breast adenocarcinoma cell line (MCF-7) via the induction of apoptosis. J. Breast Cancer 17: 314-322. https://doi. org/10.4048/jbc.2014.17.4.314

Ebrahim K, Vatanpour H, Zare A, Shirazi F.H, Nakhjavani M (2016) Anticancer activity a of caspian cobra (Naja naja oxiana) snake venom in human cancer cell lines via induction of apoptosis. Iran J. Pharm. Res. 15: 101-112. http://www.ncbi.nlm.nih.gov/pubmed/28228809

Einbond LS, Negrin A, Kulakowski DM, Wu HA, Antonetti V, Jalees F, Law W, Roller M, Redenti S, Kennelly EJ, Balick MJ (2017) Traditional preparations of kava (Piper methysticum) inhibit the growth of human colon cancer cells in vitro. Phytomedicine 24: 1-13. https://doi. org/10.1016/j.phymed.2016.11.002

Fakhri A, Omranipour R, Fakhri S, Mirshamsi M, Zangeneh F, Vatanpour H, Pourahmad J (2017) Naja Naja Oxiana venom fraction selectively induces ros-mediated apoptosis in human colorectal tumor cells by directly targeting mitochondria. Asian Pac. J. Cancer Prev. 18: 2201-2208. https://doi.org/10.22034/APJCP.2017.18.8.2201

Gasanov SE, Shrivastava IH, Israilov FS, Kim AA, Rylova KA, Zhang B, Dagda RK (2015) Naja naja oxiana cobra venom cytotoxins cti and ctii disrupt mitochondrial membrane integrity: implications for basic three-fingered cytotoxins. PLoS One 10: e0129248. https://doi. org/10.1371/journal.pone.0129248

Gillies LA, Kuwana T (2014) Apoptosis regulation at the mitochondrial outer membrane. J. Cell. Biochem. 115: 632-640. 10.1002/jcb.24709

Hanahan D, Weinberg RA (2000) The hallmarks of cancer. Cell 100: 57-70. http://www.ncbi.nlm.nih.gov/pubmed/10647931

Hus KK, Buczkowicz J, Petrilla V, Petrillova M, Lyskowski A, Legath J, Bocian A (2018) First look at the venom of Naja ashei. Molecules 23. https://doi.org/10.3390/molecules23030609

Chen KC, Liu WH, Chang LS (2010) Taiwan cobra phospholipase A2-elicited JNK activation is responsible for autocrine fas-mediated cell death and modulating $\mathrm{Bcl}-2$ and $\mathrm{Bax}$ protein expression in human leukemia K562 cells. J. Cell. Biochem. 109: 245-254. https://doi. org/10.1002/jcb.22404

Iqbal J, Abbasi BA, Ahmad R, Mahmood T, Kanwal S, Ali B, Khalil AT, Shah SA, Alam MM, Badshah H (2018) Ursolic acid a promising candidate in the therapeutics of breast cancer: Current status and future implications. Biomed. Pharmacother. 108: 752-756. https:// doi.org/10.1016/j.biopha.2018.09.096

Kale J, Osterlund EJ, Andrews DW (2018) BCL-2 family proteins: changing partners in the dance towards death. Cell Death Differ. 25: 65-80. https://doi.org/10.1038/cdd.2017.186

Kello M, Drutovic D, Chripkova M, Pilatova M, Budovska M, Kulikova L, Urdzik P, Mojzis J (2014) ROS-dependent antiproliferative effect of brassinin derivative homobrassinin in human colorectal cancer Caco2 cells. Molecules 19: 10877-10897. https://doi.org/10.3390/ molecules 190810877
Kello M, Kulikova L, Vaskova J, Nagyova A, Mojzis J (2017) Fruit peel polyphenolic extract-induced apoptosis in human breast cancer cells is associated with ROS production and modulation of p38MAPK/Erk1/2 and the Akt signaling pathway. Nutr. Cancer 69: 920-931. https://doi.org/10.1080/01635581.2017.1339819

Kerkkamp H, Bagowski C, Kool J, van Soolingen B, Vonk FJ, Vlecken D (2018) Whole snake venoms: Cytotoxic anti-metastatic and antiangiogenic properties. Toxicon 150: 39-49. https://doi. org/10.1016/j.toxicon.2018.05.004

Kini R.M, Doley R (2010) Structure function and evolution of threefinger toxins: mini proteins with multiple targets. Toxicon 56: 855867. https://doi.org/10.1016/j.toxicon.2010.07.010

Liu CC, Yang H, Zhang LL, Zhang Q, Chen B, Wang Y (2014) Biotoxins for cancer therapy. Asian Pac. J. Cancer Prev. 15: 4753-4758. http://www.ncbi.nlm.nih.gov/pubmed/24998537

Liu WH, Cheng YC, Chang LS (2009) ROS-mediated p38alpha MAPK activation and ERK inactivation responsible for upregulation of Fas and FasL and autocrine Fas-mediated cell death in Taiwan cobra phospholipase A(2)-treated U937 cells. J. Cell. Physiol. 219: 642-651. https://doi.org/10.1002/jcp.21713

Park M.H, Jo M, Won D, Song HS, Song MJ, Hong JT (2012) Snake venom toxin from Vipera lebetina turanica sensitizes cancer cells to TRAIL through ROS- and JNK-mediated upregulation of death receptors and downregulation of survival proteins. Apoptosis 17: 13161326. https://doi.org/10.1007/s10495-012-0759-5

Park MH, Son DJ, Kwak DH, Song HS, Oh KW, Yoo HS, Lee YM, Song MJ, Hong JT (2009) Snake venom toxin inhibits cell growth through induction of apoptosis in neuroblastoma cells. Arch. Pharm. Res. 32: 1545-1554. https://doi.org/10.1007/s12272-009-2106-0

Rejhova A, Opattova A, Cumova A, Sliva D, Vodicka P (2018) Natural compounds and combination therapy in colorectal cancer treatment. Eur. J. Med. Chem. 144: 582-594. https://doi.org/10.1016/j. ejmech.2017.12.039

Seydi E, Babaei S, Fakhri A, Pourahmad J (2017) Selective toxicity of Caspian cobra (Naja oxiana) venom on liver cancer cell mitochondria. Asian Pacific J. Trop. Biomed. 7: 460-465. https://doi. org/10.1016/j.apjtb.2017.01.021

Song JK, Jo MR, Park MH, Song HS, An BJ, Song MJ, Han SB, Hong IT (2012) Cell growth inhibition and induction of apoptosis by snake venom toxin in ovarian cancer cell via inactivation of nuclear factor kappa B and signal transducer and activator of transcription 3. Arch. Pharm. Res. 35: 867-876. https://doi.org/10.1007/s12272012-0512-1

Takac P, Kello M, Pilatova MB, Kudlickova Z, Vilkova M, Slepcikova P, Petik P, Mojzis J (2018) New chalcone derivative exhibits antiproliferative potential by inducing $\mathrm{G} 2 / \mathrm{M}$ cell cycle arrest mitochondrial-mediated apoptosis and modulation of MAPK signalling pathway. Chem. Biol. Interact. 292: 37-49. https://doi.org/10.1016/j. cbi.2018.07.005

Tamura Y, Simizu S, Osada H (2004) The phosphorylation status and anti-apoptotic activity of $\mathrm{Bcl}-2$ are regulated by ERK and protein phosphatase $2 \mathrm{~A}$ on the mitochondria. FEBS Lett. 569: 249-255. https://doi.org/10.1016/i.febslet.2004.06.003

Tan KK, Bay BH, Gopalakrishnakone P (2018) L-amino acid oxidase from snake venom and its anticancer potential. Toxicon 144: 7-13. https://doi.org/10.1016/j.toxicon.2018.01.015

Tischlerova V, Kello M, Budovska M, Mojzis J (2017) Indole phytoalexin derivatives induce mitochondrial-mediated apoptosis in human colorectal carcinoma cells. World J. Gastroenterol. 23: 4341-4353. https://doi.org/10.3748/wig.v23.i24.4341

Tsujimoto Y (1998) Role of Bcl-2 family proteins in apoptosis: apoptosomes or mitochondria? Genes Cells 3: 697-707. http://www.ncbi. nlm.nih.gov/pubmed/9990505

Waheed H, Moin S.F, Choudhary M.I, (2017) Snake venom: from deadly toxins to life-saving therapeutics. Curr. Med. Chem. 24: 1874 1891. https://doi.org/10.2174/0929867324666170605091546

Wang C, Youle RJ (2009) The role of mitochondria in apoptosis. Annu. Rev. Genet. 43: 95-118. 10.1146/annurev-genet-102108-134850 Wu MY, Ming W, Tang Y, Zhou SM, Kong TH, Dong WH (2013) The anticancer effect of cytotoxin 1 from Naja Atra cantor venom is mediated by a lysosomal cell death pathway involving lysosomal membrane permeabilization and cathepsin B release. Am. J. Chin. Med. 41: 643-663. https://doi.org/10.1142/S0192415x13500456

Wuster W, Broadley DG (2007) Get an eyeful of this: a new species of giant spitting cobra from eastern and north-eastern Africa (Sq uamata:Serpentes:Elapidae:Naja) Zootaxa 51-68. <Go to ISI>:// WOS:000248350300004 